Case Report

\title{
Large Left Ventricular Thrombus in a Patient with Systemic and Venous Thromboembolism Secondary to Protein C and S Deficiency
}

\author{
Mohit Pahuja, ${ }^{1}$ Bujji Ainapurapu, ${ }^{2}$ and Aiden Abidov ${ }^{3,4}$ \\ ${ }^{1}$ Department of Medicine, St. Joseph's Hospital and Medical Center, Phoenix, AZ, USA \\ ${ }^{2}$ Department of Medicine, Banner University Medical Center, Tucson, AZ, USA \\ ${ }^{3}$ Section of Cardiology, John D. Dingell VA Medical Center, Detroit, MI, USA \\ ${ }^{4}$ Department of Medicine, Wayne State University, Detroit, MI, USA
}

Correspondence should be addressed to Aiden Abidov; aiden.abidov@wayne.edu

Received 21 September 2016; Accepted 15 December 2016; Published 4 January 2017

Academic Editor: Tayfun Sahin

Copyright (C) 2017 Mohit Pahuja et al. This is an open access article distributed under the Creative Commons Attribution License, which permits unrestricted use, distribution, and reproduction in any medium, provided the original work is properly cited.

\begin{abstract}
58-year-old Hispanic female presented with an altered mental status. A CT scan of the head demonstrated multiple scattered infarcts and a large right temporal lobe infarct. We also diagnosed the patient with right popliteal and femoral vein thrombosis, bilateral pulmonary embolism, and a transient right radial artery occlusion. Her 12-lead EKG showed lateral ST elevation. Emergent coronary angiogram revealed normal coronaries. Echocardiogram demonstrated a large mobile mass attached to the anterolateral free wall with overall normal contractility of the left ventricle. The patient underwent surgical embolectomy to prevent further systemic embolization. Coagulability workup returned positive for protein C and S deficiency. The patient did well after surgery. Following her surgery, we initiated chronic oral anticoagulation. The presentation with intracardiac thrombus in a normal heart should raise a concern of a probable thrombophilia.
\end{abstract}

\section{Introduction}

Protein $\mathrm{C}$ and $\mathrm{S}$ deficiency is an uncommon type of thrombophilic genetic syndromes. Deficiency of both protein C and $\mathrm{S}$ may result in increased risk of venous and arterial thrombosis [1]. Cases of cardiac/nonvascular thrombosis appear to be exceptionally rare $[2,3]$.

We present a case of a patient admitted with a right temporal lobe infarct along with bilateral segmental pulmonary embolism and deep vein thrombosis. Further workup revealed a large mobile left ventricular thrombus. Hematological workup revealed findings consistent with combined protein $\mathrm{C}$ and $\mathrm{S}$ deficiency. The patient underwent an urgent surgical cardiac thrombectomy and was subsequently treated with anticoagulation therapy.

\section{Case Presentation}

A 58-year-old Hispanic female with a history of hypertension and hyperlipidemia was brought to the emergency department for an altered mental status. On admission, the patient was hemodynamically stable. She had a nonfocal initial neurologic exam. Her laboratory findings were consistent with hypoxemia, acidosis, and mildly elevated leukocytosis. A 12-lead ECG revealed sinus tachycardia with lateral ST segment elevation; due to these findings, the patient underwent emergent cardiac catheterization, which revealed normal coronaries.

A noncontrast $\mathrm{CT}$ scan of the head demonstrated a right subacute temporal lobe infarct and multiple scattered infarcts in all vascular territories raising the possibility of embolic phenomenon. Further clinical course was complicated by right popliteal and superficial femoral vein thrombosis and bilateral segmental pulmonary embolism. The patient also had a transient right radial artery occlusion.

Her initial contrast-enhanced transthoracic echocardiography (performed after the cardiac catheterization) and subsequent transesophageal echocardiography (TEE) revealed a large left ventricular mass with a wide base, attached to the 


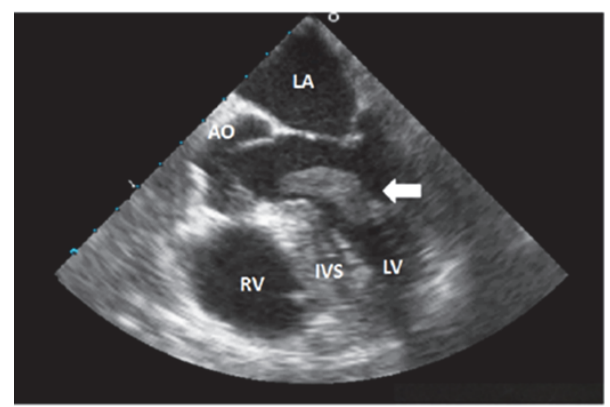

Figure 1: Large mass in the left ventricle (white arrow) extending into the left ventricular outflow tract. $\mathrm{AO}=$ aortic root; IVS = interventricular septum; LA = left atrium; $L V=$ left ventricle; $R V=$ right ventricle.

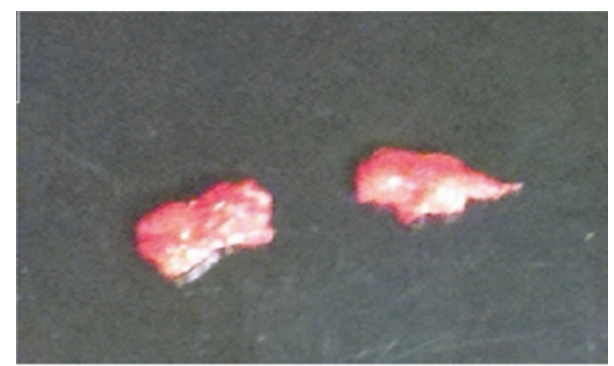

FIGURE 2: Intraoperative photograph demonstrates a large elongated soft pink-tan thrombus excised from the left ventricle. Due to its size, the thrombus was extracted in 2 pieces.

anterolateral free wall. The mass had poorly defined edges and several mobile components. There were no other significant structural and functional cardiac abnormalities noted. Detailed TEE analysis (Figure 1, Supplementary video in Supplementary Material available online at https://doi.org/10 $.1155 / 2017 / 7576801$ ) confirmed a presence of a $42 \times 10 \mathrm{~mm}$ thrombus arising from the lateral wall and extending into the left ventricular outflow tract.

Evidence of multiple arterial and venous clots in addition to the large cardiac thrombus raised the suspicion for inherited thrombophilia. The coagulability workup was performed and came back positive for protein $\mathrm{C}$ and $\mathrm{S}$ deficiency, with activity of $26 \%$ (normal range: $84-171$ ) and $18 \%$ (normal range: $54-132 \%$ for females) for proteins $\mathrm{C}$ and $\mathrm{S}$, respectively. At that time, the patient had normal liver function and vitamin $\mathrm{K}$ level and was not on any vitamin $\mathrm{K}$ antagonist therapy. Renal function was normal and the patient did not have any evidence of disseminated intravascular coagulation.

The patient underwent a surgical cardiac thrombectomy to prevent further systemic embolization. An elongated mass attached to the lateral wall and connected to anterior mitral leaflet was removed (Figure 2). No valvular changes or lateral wall regional wall motion abnormalities were observed. Pathology confirmed an organizing arterial thrombus without evidence of infection. The patient did well after surgery and was treated with oral anticoagulation (Warfarin, bridged with intravenous Heparin) and discharged to skilled nursing facility with no further cardiac or vascular complications.

\section{Discussion}

Protein $\mathrm{C}$ and protein $\mathrm{S}$ are vitamin $\mathrm{K}$-dependent plasma proteins. Activated protein $\mathrm{C}$ in the presence of protein $\mathrm{S}$ inhibits activated coagulation factors V and VIII. Protein S acts as cofactor for the protein C system. Both protein $\mathrm{C}$ and $\mathrm{S}$ deficiency are autosomal dominant genetic disorders, usually manifesting as venous thromboembolism with deep and superficial vein thrombosis, pulmonary embolism, or both. Rarely, protein C and S deficiency is associated with an arterial thrombosis as well as nonhemorrhagic stroke [4-6]. In a cohort study containing three cohorts of families with a hereditary deficiencies of protein C, protein S, and antithrombin III, compared with nondeficient family members, subjects with protein $\mathrm{S}$ or protein $\mathrm{C}$ deficiency but not antithrombin III deficiency had a higher risk for arterial thromboembolism before 55 years of age that was independent of their history of prior venous thromboembolism [4]. In the ARIC (Atherosclerosis Risk in Communities) study, ischemic stroke had a negative but nonsignificant association with protein $\mathrm{C}$ levels after adjustment for all other risk factors [7].

Intracardiac thrombus formation can occur in patients with protein $\mathrm{C}$ and $\mathrm{S}$ deficiency but is relatively rare in comparison to venous and arterial thrombosis. Most of the cases reported association with other risk factors such as high altitude, left ventricular dysfunction, or dilated cardiomyopathy [2, 3, 8-10]. Possible mechanisms include increased hyperviscosity due to dehydration, stasis, and decreased intracardiac blood flow [11-13]. It is unusual to develop intraventricular thrombus with a normal contractility in absence of cardiomyopathy with either global or regional left ventricular dysfunction. In this regard, Özkutlu et al. demonstrated that three out of eleven patients with intracardiac thrombus and otherwise normal heart had protein $\mathrm{C}$ deficiency [14]. Our patient did not have any cardiomyopathy or left ventricular dysfunction. We report an extremely rare case of such an extensive mobile cardiac thrombus with multiple arterial and venous embolic events with combined protein $\mathrm{C}$ and $\mathrm{S}$ deficiency. We propose that patients presenting with large intraventricular thrombus should be checked for protein $\mathrm{C}$ and $\mathrm{S}$ deficiency especially when associated with venous and arterial thrombosis.

Currently there are no guidelines available for the management of intracardiac thrombus. The majority of the patients are placed on anticoagulation therapy. Lee et al. proposed that, in comparison to patients with nonpedunculated thrombi, patients with mural pedunculated thrombi are at increased risk for both systemic embolization and recurrent embolism despite anticoagulation therapy. Risk of systemic embolization was higher in patients on anticoagulant therapy compared to surgical therapy (17.7\% versus $0 \%)$ [15]. Surgical thrombectomy appears to be clinically effective in cases with mobile pedunculated thrombi [16-20]. In our case, due to multiple embolic phenomena and increased risk of new embolization in this patient with thrombophilia, we decided 
to proceed with surgical thrombectomy with an excellent clinical outcome.

\section{Conclusion}

We conclude that protein $\mathrm{C}$ and $\mathrm{S}$ deficiency should be considered in the differential diagnosis in patients presenting with intracardiac and systemic thrombosis. Advanced cardiovascular imaging may prove useful in determining the need for surgical thrombectomy. Systemic anticoagulation therapy is the most appropriate therapeutic option in patients with intracardiac and systemic thrombosis.

\section{Competing Interests}

The authors declare that they have no competing interests.

\section{Authors' Contributions}

Mohit Pahuja was responsible for final draft and review of literature. Bujji Ainapurapu was responsible for study design, data collection, and preparing initial draft. Aiden Abidov was responsible for study design, data collection, and providing critical review.

\section{Acknowledgments}

The authors are indebted to Christine Marie Kneisel M.D., and M. Cristina Smith M.D., for their expert input in preparation of this manuscript.

\section{References}

[1] J. Mateo, A. Oliver, M. Borrell, N. Sala, and J. Fontcuberta, "Laboratory evaluation and clinical characteristics of 2,132 consecutive unselected patients with venous thromboembolismresults of the Spanish multicentric study on thrombophilia (EMET-Study)," Thrombosis and Haemostasis, vol. 77, no. 3, pp. 444-451, 1997.

[2] S. Malani, D. Chadha, and A. Banerji, "Biventricular thrombosis in a structurally normal heart at high altitude," BMJ Case Reports, vol. 2014, 2014.

[3] F. A. Paç and D. N. Çagdas, "Treatment of massive cardiac thrombi in a patient with protein $\mathrm{C}$ and protein $\mathrm{S}$ deficiency," Blood Coagulation and Fibrinolysis, vol. 18, no. 7, pp. 699-702, 2007.

[4] X. Douay, C. Lucas, C. Caron, J. Goudemand, and D. Leys, "Antithrombin, protein $\mathrm{C}$ and protein S levels in 127 consecutive young adults with ischemic stroke," Acta Neurologica Scandinavica, vol. 98, no. 2, pp. 124-127, 1998.

[5] B. K. Mahmoodi, J.-L. P. Brouwer, N. J. G. M. Veeger, and J. Van Der Meer, "Hereditary deficiency of protein C or protein $S$ confers increased risk of arterial thromboembolic events at a young age. Results from a large family cohort study," Circulation, vol. 118, no. 16, pp. 1659-1667, 2008.

[6] A. Onwuanyi, R. Sachdeva, K. Hamiram, M. Islam, and R. Parris, "Multiple aortic thrombi associated with protein C and S deficiency," Mayo Clinic Proceedings, vol. 76, no. 3, pp. 319-322, 2001.
[7] A. R. Folsom, W. D. Rosamond, E. Shahar et al., "Prospective study of markers of hemostatic function with risk of ischemic stroke," Circulation, vol. 100, no. 7, pp. 736-742, 1999.

[8] D.-Y. Kim, S. Islam, N. T. Mondal, F. Mussell, and M. Rauchholz, "Biventricular thrombi associated with peripartum cardiomyopathy," Journal of Health, Population and Nutrition, vol. 29, no. 2, pp. 178-180, 2011.

[9] S. Kumar, N. Moorthy, S. Yadav, A. Kapoor, and D. C. Dale, "Thyroid storm presenting as congestive heart failure and protein-S deficiency-induced biventricular and internal jugular venous thrombii," Journal of Postgraduate Medicine, vol. 59, no. 3, pp. 229-231, 2013.

[10] K. S. Nair, A. Weerasinghe, M. Dahdal, J. Simon, R. Gibbs, and J. R. Anderson, "Cardiac intraventricular thrombus in protein C deficiency," Journal of the Royal Society of Medicine, vol. 94, no. 12, pp. 641-642, 2001.

[11] E. F. Mammen, "Pathogenesis of venous thrombosis," Chest, vol. 102 , no. 6, 1992.

[12] G. B. Segel and C. W. Francis, "Anticoagulant proteins in childhood venous and arterial thrombosis: a review," Blood Cells, Molecules, and Diseases, vol. 26, no. 5, pp. 540-560, 2000.

[13] M. Yasaka, T. Yamaguchi, T. Miyashita, Y.-D. Park, T. Sawada, and T. Omae, "Predisposing factors of recurrent embolization in cardiogenic cerebral embolism," Stroke, vol. 21, no. 7, pp. 10001007, 1990.

[14] S. Özkutlu, N. Özbarlas, Ş. Özme, M. Saraçlar, S. Gögüş, and M. Demircin, "Intracardiac thrombosis diagnosed by echocardiography in childhood: predisposing and etiological factors," International Journal of Cardiology, vol. 40, no. 3, pp. 251-256, 1993.

[15] J. M. Lee, J. J. Park, H. W. Jung et al., "Left ventricular thrombus and subsequent thromboembolism, comparison of anticoagulation, surgical removal, and antiplatelet agents," Journal of Atherosclerosis and Thrombosis, vol. 20, no. 1, pp. 73-93, 2013.

[16] E. Cousin, M. Scholfield, C. Faber, C. Caldeira, and M. Guglin, "Treatment options for patients with mobile left ventricular thrombus and ventricular dysfunction: a case series," Heart, Lung and Vessels, vol. 6, no. 2, pp. 88-91, 2014.

[17] J. Leick, S. Szardien, C. Liebetrau et al., "Mobile left ventricular thrombus in left ventricular dysfunction: case report and review of literature," Clinical Research in Cardiology, vol. 102, no. 7, pp. 479-484, 2013.

[18] R. M. John, M. F. Sturridge, and R. H. Swanton, "Pedunculated left ventricular thrombus-report of two cases," Postgraduate Medical Journal, vol. 67, no. 791, pp. 843-845, 1991.

[19] M. Nili, E. Deviri, R. Jortner, B. Strasberg, and M. J. Levy, "Surgical removal of a mobile, pedunculated left ventricular thrombus: report of 4 cases," Annals of Thoracic Surgery, vol. 46, no. 4, pp. 396-400, 1988.

[20] A. Mager, B. Strasberg, M. Nili et al., "Surgical removal of echocardiographically detected multiple pedunculated and mobile left ventricular thrombi in acute myocardial infarction," Israel Journal of Medical Sciences, vol. 25, no. 11, pp. 639-641, 1989. 


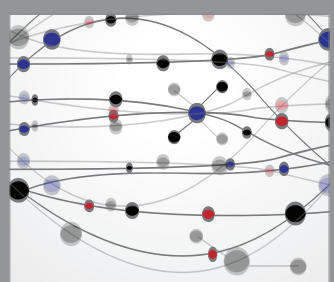

The Scientific World Journal
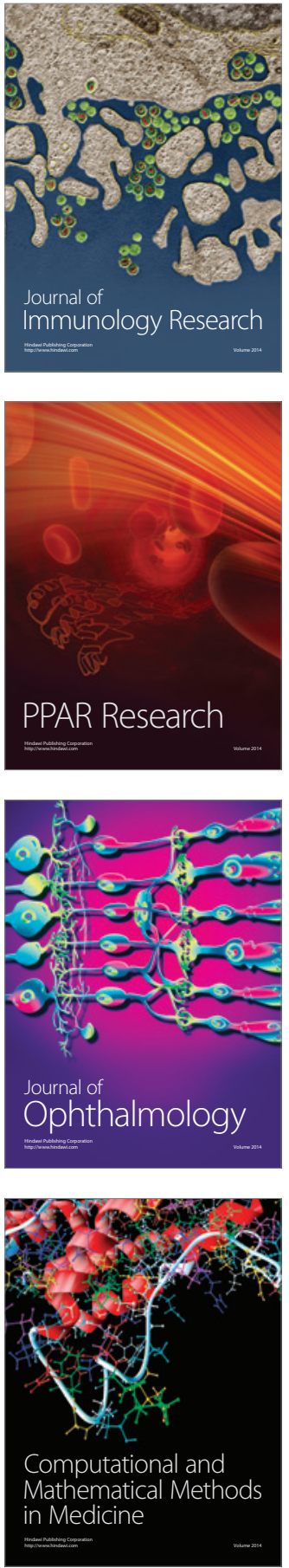

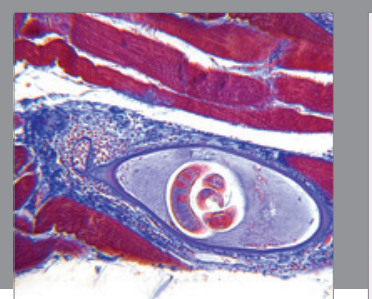

Gastroenterology Research and Practice
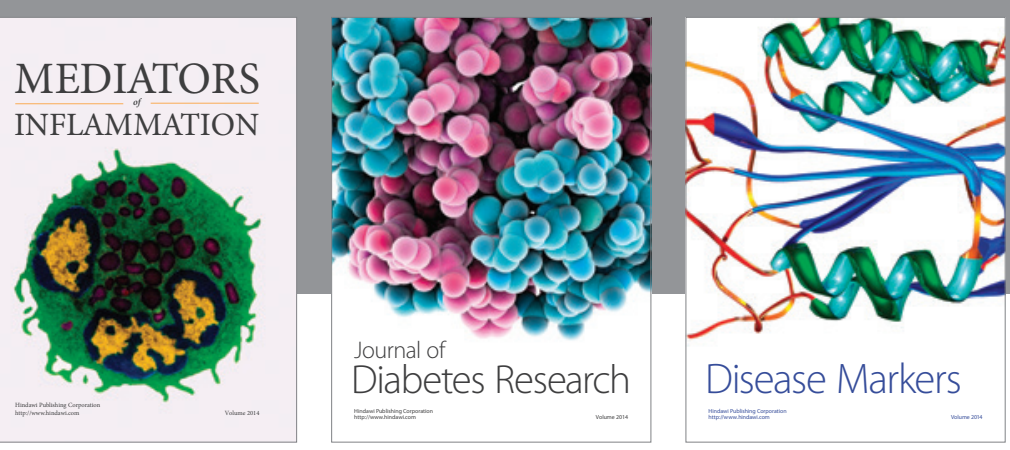

Disease Markers

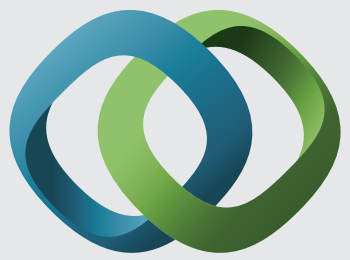

\section{Hindawi}

Submit your manuscripts at

https://www.hindawi.com
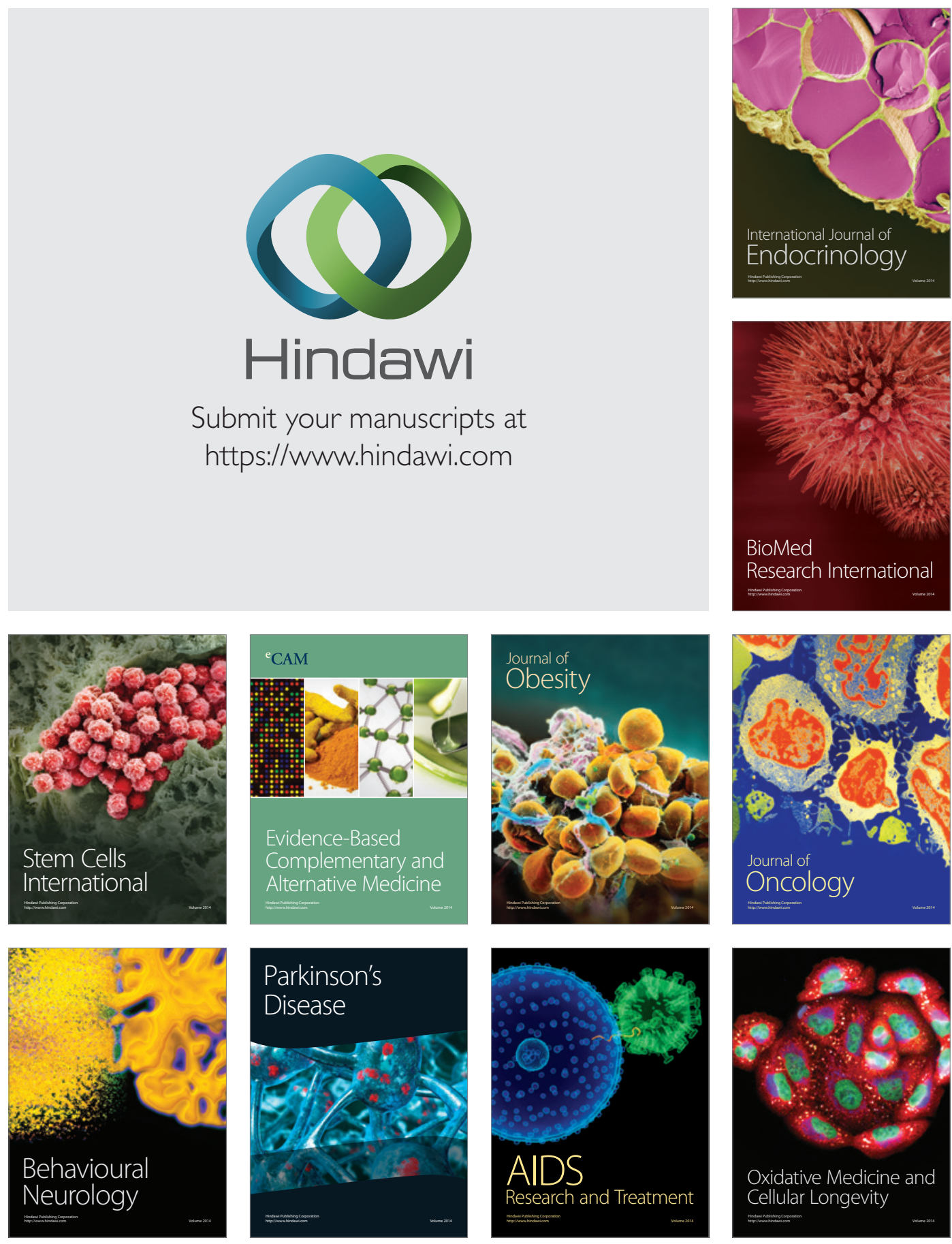